LA W RENCE LIVERMORE N A TIONAL LABORATORY
REPORT ON THE NDC CAPACITY BUILDING AND REGIONAL SEISMIC TRAVEL TIME WORKSHOP AND TRAINING

S. C. Myers, M. L. Begnaud

November 7, 2013 
This document was prepared as an account of work sponsored by an agency of the United States government. Neither the United States government nor Lawrence Livermore National Security, LLC, nor any of their employees makes any warranty, expressed or implied, or assumes any legal liability or responsibility for the accuracy, completeness, or usefulness of any information, apparatus, product, or process disclosed, or represents that its use would not infringe privately owned rights. Reference herein to any specific commercial product, process, or service by trade name, trademark, manufacturer, or otherwise does not necessarily constitute or imply its endorsement, recommendation, or favoring by the United States government or Lawrence Livermore National Security, LLC. The views and opinions of authors expressed herein do not necessarily state or reflect those of the United States government or Lawrence Livermore National Security, LLC, and shall not be used for advertising or product endorsement purposes.

This work performed under the auspices of the U.S. Department of Energy by Lawrence Livermore National Laboratory under Contract DE-AC52-07NA27344. 


\title{
REPORT ON THE NDC CAPACITY BUILDING AND REGIONAL SEISMIC TRAVEL TIME WORKSHOP AND TRAINING \\ 14-18 October 2013
}

\author{
San Juan, Argentina \\ Instituto Nacional de Prevención Sísmica \\ INPRES
}

\author{
Stephen Myers, Lawrence Livermore National Laboratory \\ Michael Begnaud, Los Alamos National Laboratory
}

Drs. Stephen Myers and Michael Begnaud represented the U.S. at the National Data Center Capacity Building and Regional Seismic Travel Time Workshop and Training, which was held at the Instituto Nacional de Prevención Sísmica (INPRES) in San Juan, Argentina from 14 to 18 October 2013. This report focuses on the Regional Seismic Travel Time (RSTT) half of the workshop.

Workshop participants included representatives from 17 Latin American countries, the U.S., U.K., and the CTBTO. Appendix I contains the list of participants.

Table 1: Countries and Organizations Represented

\begin{tabular}{|l|l|l|}
\hline Argentina & Dominican Republic & Panama \\
\hline Bahamas & Ecuador & Paraguay \\
\hline Bolivia & Guatemala & Inter. Seisolo. Center: U.K. \\
\hline Brazil & Haiti & LLNL, LANL: U.S. \\
\hline Chile & Jamaica & Venezuela \\
\hline Colombia & Mexico & CTBTO \\
\hline Costa Rica & Nicaragua & \\
\hline
\end{tabular}

The first half of the week was dedicated to national data center (NDC) capacity building. Presentations by representatives of the Comprehensive Nuclear-Test-Ban Treaty Organization (CTBTO) provided overviews of

- CTBT goals and objectives,

- The role of States-Parties to the CTBT,

- Operation of the International Data Center (IDC),

- The role of NDCs,

- Products available to NDCs from the IDC,

- Capacity building efforts in Latin America, and

The NDC workshop also included reports and statements from workshop participants on their seismic networks and CTBT-related activities.

The workshop agenda is provided in Appendix II. 
Appendix III has a selection of photos from the workshop.

The RSTT half of the workshop had the following goals

- Introduce RSTT method and describe why it can help CTBTO and NDCs,

- Demonstrate improved seismic-event location using RSTT

- Provide hands-on training for using RSTT with a location program

- Describe the RSTT outreach effort

- Integrate the results of participants' geophysical studies into the RSTT model.

- Solicit contributions of "ground-truth" event locations and associated arrival-time measurements to the ISC repository.

- Foster a collaborative effort to update the RSTT model using seismic tomography.

- Provide hands-on training on how to update the RSTT model.

Overview of Selected RSTT Presentations

Dr. Stephen Myers provided an overview of the RSTT effort. The presentation included a description of the model parameterization and the method of travel time calculation. Millisecond RSTT computation time on readily available computers was emphasized, because it is this feature that makes RSTT accessible/usable by most of the participants. Later in the workshop, Dr. Myers demonstrated the RSTT Node Get and Set (RSTT_NOGS) utilities that allow users to output RSTT model parameters to ASCII files, edit the ASCII files, and upload the edits to a new RSTT model. RSTT_NOGS enables users to experiment with the effect of model changes on regional travel times.

Dr. Marcelo Assumpcao from the University of Sao Paulo, Brazil showed locations of several earthquakes along the Andes Mountains - which is where most seismicity occurs in South America - using conventional travel time methods and RSTT. Locations based on local seismic deployments are available for each of the events used in his study, providing epicenter accuracy of approximately 5 kilometers. Locations determined using a regional network and conventional travel time methods were shown to be biased by tens of kilometers. For the specific example events from Dr. Assumpcao a location bias of 50 kilometers was observed. Locations determined using a regional network and RSTT were shown to be within $10 \mathrm{~km}$ of the local-network location and bias was significantly mitigated. Dr. Assumcao's independent assessment of RSTT performance carried considerable weight with the participants.

Dr. Jordi Julia and from the Federal University of Northern Rio Grande (Brazil) presented on research efforts to develop a new model of crustal thickness for South America. This work has been done jointly with Dr. Assumpcao at University of Sao Paulo. The new model differs significantly from the global model of crustal thickness on which RSTT is currently based. Because regional travel times can be quite sensitive to crustal thickness and RSTT tomography does not attempt to change crustal thickness, 
incorporation of Dr. Assumpcao's and Dr. Julia's crustal thickness model into the RSTT model was deemed a top priority. Dr. Myers used RSTT_NOGS to make this update.

Dr. Istvan Bondar from the International Seismological Center (ISC) presented on efforts to collect ground truth events globally. Because exact ground truth events (perfectly known location and origin time) with clear regional (much less global) signals are so rare, the seismic community extends the term "ground truth" to include uncommonly wellconstrained locations that utilize a local network within $200 \mathrm{~km}$ of the event. The ISC ground truth database is openly available on the web (http://www.isc.ac.uk/gtevents/). Prior to the RSTT outreach effort in South America, the ISC ground truth database included only a few events that were gleaned from global bulletins. These ground truth events were clustered in 3 locales along the Andes Mountains. RSTT outreach has prompted contribution of dozens of new ground truth events. Most importantly, the new events are distributed throughout South America, providing new constraints on the RSTT model. In addition to the ISC ground truth database, Dr. Bondar described his ISC location code, which has been modified to work with RSTT. The ISC location code can be downloaded from http://www.isc.ac.uk/iscbulletin/iscloc/index.php.

Dr. Michael Begnaud gave an overview of tomographic imaging methods that have been used to optimize RSTT seismic wave speed for travel time prediction accuracy. Data sets and tomographic results for Eurasia, North America, and South America were presented. The presentation demonstrated that RSTT efforts in Latin America have contributed significantly to data coverage across South America, but holes in data coverage remain. Later in the workshop, Dr. Begnaud presented a new RSTT model. The new model is based on a tomographic inversion that includes data contributed through RSTT outreach activities. The results demonstrated that RSTT outreach activities have significantly improved data quality and coverage across South America and the Caribbean. Many of the South American researchers identified additional regional data for the tomography effort and suggested that they will continue to gather and provide this data for future efforts.

\section{Students Funded Under RSTT Outreach}

The U.S. funded two Argentine students through the CTBTO to work on data collection and model development at INPRES. The students are Brahim Aguil and Agostina Venerdini. Mr. Aguil and Ms. Venerdini have worked on RSTT-related projects since the Fall (southern hemisphere) of 2013, and they presented on their accomplishments at the workshop. Their accomplishments include: recovering seismic arrival times associated with ground-truth events from the INPRES database; relocating events using a local network to add to the ground truth database; and developing new models of the crust for locales near San Juan, Argentina. They have made good progress in their efforts and their work should continue. The students are currently attending the National University of San Juan and both plan to graduate in Summer or Fall (southern hemisphere) of 2014. After graduating Mr. Aguil and Ms. Venerdini U.S. will continue their work at INPRES under the funding provided by the U.S./CTBTO.

\section{Hands On Exercises}


The CTBTO rented approximately 10 PC laptops to facilitate hands-on activities. The PCs included a Linux virtual machine with copies of the NDC-In-A-Box software and the ISC locator. Prior to the workshop Drs. Bondar and Myers distributed a set of ground truth events and requested that participants contribute arrival times and/or waveforms associated with those events to the workshop. Data formatting issues precluded full use of waveform data, but the GeoTool software, which is part of NDC-In-A-Box, was used to view some contributed waveforms. Following an instructional presentation by Dr. Bondar on the use of the ISC locator, workshop participants were able to relocate events using RSTT. Likewise, workshop participants were able use the RSTT_NOGS codes to output RSTT model parameters, modify the parameters, and upload to a new model. We find that detailed instruction and hands-on activities are essential to achieving the goal of widespread use/adoption of the RSTT method at Latin American NDCs and research institutions.

\section{Future Activities}

The CTBTO coordinator for RSTT Latin America outreach, Dr. Federico Guendel announced that he plans to hold an RSTT workshop in Central America in the Spring of 2014. The workshop will follow the format established in San Juan. We expect an announcement from the CTBTO about the Central America workshop in December of 2013 or January of 2014.

The Regional Assembly of the Latin American and Caribbean Seismological Commission will hold a profession conference from July 23-25, 2014 in Bogota, Columbia. Dr. Assumpcao and other workshop participants suggested that RSTT collaborators meet on the margins of that conference to discuss their uses of RSTT and provide feedback to the U.S. National Laboratories. 


\section{Appendix I: List of participants}

\begin{tabular}{|c|c|c|c|}
\hline Name & & & Country \\
\hline $\mathrm{Mr}$ & Juan Pablo & Aguiar & Argentina \\
\hline $\mathrm{Mr}$ & Mario Antonio & Bufaliza & Argentina \\
\hline $\mathrm{Mr}$ & Marcelo Pablo & Moreno Zuanni & Argentina \\
\hline $\mathrm{Mr}$ & Rodolfo Rafael & Recio & Argentina \\
\hline $\mathrm{Mr}$ & Horacio Daniel & Sanchez & Argentina \\
\hline $\mathrm{Mr}$ & Richardo Gabriel & Sifon & Argentina \\
\hline $\mathrm{Mr}$ & Brahim & Aguil & Argentina \\
\hline $\mathrm{Mr}$ & Mario Rubén & Fernández & Argentina \\
\hline Ms & Luciana & López & Argentina \\
\hline $\mathrm{Mr}$ & Gerardo Raúl & Sánchez Girino & Argentina \\
\hline Ms & Veneridini & Agostina & Argentina \\
\hline $\mathrm{Mr}$ & Javier & Santo & Argentina \\
\hline $\mathrm{Mr}$ & Paul Alexander & Coleman & Jamaica \\
\hline $\mathrm{Mr}$ & Francisco Antonio & Peralta Belmonte & Paraguay \\
\hline $\mathrm{Mr}$ & Dmitry & Storchak & UK \\
\hline $\mathrm{Mr}$ & Istvan & Bondar & UK \\
\hline $\mathrm{Mr}$ & Laverne Shezelle & Mather & Bahamas \\
\hline Ms & Teddy & Grifiths & Bolivia \\
\hline $\mathrm{Mr}$ & Marcelo Sousa de & Assumpcao & Brazil \\
\hline $\mathrm{Mr}$ & Jordi & Julia Casas & Brazil \\
\hline $\mathrm{Mr}$ & Sebastian & Riquelme & Chile \\
\hline Ms & Patricia & Pedraza Garcia & Colombia \\
\hline $\mathrm{Mr}$ & Hugo Esteban & Poveda Nunez & Colombia \\
\hline $\mathrm{Mr}$ & Ronnie & Quintero & Costa Rica \\
\hline $\mathrm{Mr}$ & Jose Ramon & Delgado Nin & Dominican Republic \\
\hline $\mathrm{Mr}$ & Felix & Martinez & Dominican Republic \\
\hline $\mathrm{Mr}$ & Mario & Ruiz & Ecuador \\
\hline $\mathrm{Mr}$ & Nelson Javier & Santo & Ecuador \\
\hline $\mathrm{Mr}$ & Luis Alberto & Bautista & Guatemala \\
\hline $\mathrm{Mr}$ & Robin Onelio & Yani Quiyuch & Guatemala \\
\hline $\mathrm{Mr}$ & Frantz & SAINT-PREUX & Haiti \\
\hline Ms & Karleen Marie & Black & Jamaica \\
\hline $\mathrm{Mr}$ & Laurel Anthony & Choy & Jamaica \\
\hline $\mathrm{Mr}$ & Victor Hugo & Espindola Castro & Mexico \\
\hline $\mathrm{Mr}$ & Creyving Jose & Arguello Miranda & Nicaragua \\
\hline Ms & Martha Vanessa & Herrera Jimenez & Nicaragua \\
\hline $\mathrm{Mr}$ & Nestor Antonio & Luque Vergara & Panama \\
\hline $\mathrm{Mr}$ & Juan Carlos & Velazquez Monzon & Paraguay \\
\hline $\mathrm{Mr}$ & Moises Alejandro & Gadea Villalba & Paraguay \\
\hline
\end{tabular}




$\begin{array}{llll}\text { Mr } & \text { Edmundo } & \text { Norabuena } & \text { Peru } \\ \text { Mr } & \text { Herbert } & \text { Rendon } & \text { Venezuela } \\ \text { Mr. } & \text { Michael } & \text { Begnaud } & \text { U.S.A } \\ \text { Mr. } & \text { Stephen } & \text { Myers } & \text { U.S.A } \\ \text { Mr. } & \text { Federico } & \text { Guendel } & \text { CTBTO } \\ \text { Mr. } & \text { Jeffrey } & \text { Given } & \text { CTBTO } \\ \text { Ms. } & \text { Misrak } & \text { Fesseha } & \text { CTBTO }\end{array}$




\title{
Appendix II: Workshop Agenda
}

DRAFT PROGRAMME AGENDA

\section{NDC CAPACITY BUILDING AND REGIONAL SEISMIC TRAVEL TIME WORKSHOP AND TRAINING}

\author{
14-18 October 2013 \\ San Juan, Argentina \\ Instituto Nacional de Prevención Sísmica \\ INPRES
}

Monday, 14 October 2013

09:00-09:45 Registration of Participants

09:45- 10:00 Welcoming remarks:

- Representative from host Country: Welcoming speech by Mr. Alejandro GIULIANO, Director General of INPRES

- Representative from, Preparatory Commission for the Comprehensive Nuclear-Test-Ban Treaty Organization (CTBTO) : Workshop overview and expectations by $\mathbf{M r}$. Jeffrey GIVEN, Chief of Software Applications Section

10:00-10:30 Status of Capacity Building Project in Latin America and the Caribbean's: Current State of Data \& Product Usage in LAC Region, Latest developments and Future Plans.

- Ms. Misrak FISSEHA (IDC)

10:30 - 11:00 Coffee Break and Group Photo

11:00-12:00 Integrating IMS data with National/Regional data, Capacity Building Systems Installations, NDC Training and NDC Follow up Visits in LAC region: Experience \& Lessons Learned

- Mr Ronnie QUINTERO (Costa Rica NDC)

12:00- 12:30 Follow-up Exercises on NDC Trainings and National Preparedness Exercises (NPE): Experience \& Lessons Learned

- Mr. Jeffrey GIVEN (IDC) 
12:30-13:30 Lunch break

13:30 - 15:00 National Experiences in Establishing and Operating an NDC:

Presentations by Capacity Building Beneficiary Countries (I5Min.each)

- Mr. Jeffrey GIVEN, Mr. Federico GUENDEL and Ms. Misrak FISSEHA (Moderators)

- Argentina

- Bahamas

- Bolivia

- Brazil

- Chile

- Colombia

- Costa Rica

- Dominican Republic

- Ecuador

- Guatemala

- Haiti

- Jamaica

- Mexico

- Nicaragua

- Panama

- Paraguay

- Peru

- Venezuela

$15: 00-15: 30$

Coffee Break

15:30 - 16:00 NDC-in-a-Box Extension: Radionuclide software given by the PTS for the States Parties and future inclusion of Seiscomp3

- Mr. Jeffrey GIVEN (IDC)

16:00 - 17:30 Discussion on the following topics:

- Capacity building for establishing an NDC,

- Technical assistance, training and software needs

- Usage of IMS Data and IDC products:

- Updating Information on Current NDC Status:

- Fostering cooperation between NDCs;

- Cooperation and collaboration between States and CTBTO.

- Review of Country Profiles - update authorised users using NDC Registration form 
- Integrating IMS Data with National/Regional data: RSTT project and data sharing activities.

- Civil and scientific applications of IMS data and IDC products with emphasis on special interest to NDCs in Latin America and the Caribbean.

17:00-17:30 Results of the Discussion

\section{Tuesdav, 15 October 2013}

09:00-09:30 Potential uses of IMS Data and IDC Products for Civil and Scientific Applications: Examples from Seismic, Hydroacoustic Infrasound and Radionuclide technologies

$09: 30-10: 30$

- Ms. Misrak FISSEHA (IDC)

Selected presentation on National Experiences on the Use of IMS data and IDC products for Civil and Scientific Applications

- Seismic

- "Improving location of regional events in South America with IMS stations and 3D models"

- Mr. M. Assumpcao, University of Sao Paulo, Sao Paulo, Brazil

- Seismic, Hydroacoustic and Infrasound

- Uses of IMS data for Tsunami Warning System - Mr. Ronnie QUINTERO, Universidad Nacional De Costa Rica, Costa Rica NDC

- Infrasound

- Infrasound Signals from Itaipu dam and Iguazu falls - Mr. Juan Carlos Velazquez and Mr. Moises Alejandro Gadea Villalba Universidad Nacional de Asuncion, Paraguay NDC

10:30-11:00 Coffee Break

11:00 - 12:30 Round Table Discussion on Lesson Learned: emphasis on the possible relevant civil and scientific applications of IMS data and IDC products in Latin Amcrica and the Caribbean region.

- Mr. Jeffrey GIVEN, Mr. Federico GUENDEL and Ms. Misrak FISSEHA (Moderators)

12:30-13:30 Lunch break 
13:30-15:00 Round Table Discussion on Lesson Learned: Future Needs Assessment, Feed back to the PTS from National Experiences on what the PTS can do for improved Capacity Building in terms of:

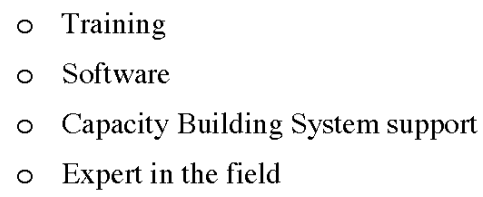

- Mr. Jeffrey GIVEN, Mr. Federico GUENDEL and Ms. Misrak FISSEHA (Moderators)

15:00-15:30 Coffee Break

15:30-17:30 Round Table Discussion on Lesson Learned: Future Needs Assessment, Feed back to the PTS from National Experiences on what the PTS can do for improved Capacity Building in terms of:

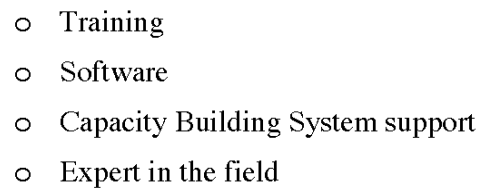

- Mr. Jeffrey GIVEN, Mr. Federico GUENDEL and Ms. Misrak FISSEHA (Moderators)

Wednesday, 16 October 2013

09:00 - 09:30 Overview of RSTT project: involvement of LAC region

- Mr. Jeffrey GIVEN and Mr. Federico GUENDEL

09:30 - 10:00 Demonstration of the CTBT Link to the International Seismological Centre ISC Database

- Mr. Dmitry A. Storchak

10:00 - 10:30 Wrap-Up Discussions: Suggestions \& Recommendations for Increased Use of IMS Data and IDC Products including possible use for Civil and Scientific applications. Discussion points to formulate Recommendations/Suggestions for future Capacity Building efforts:

- Identifying needs on Technical assistance from PTS for establishing/strengthening NDC

- Increasing Use of IMS Data and IDC products in LAC

- Fostering cooperation between NDCs

- Establishing the Legal and Institutional Framework Nationally

- Cooperation and collaboration between States and CTBTO

- Mr. Jeffrey GIVEN, Mr. Federico GUENDEL and Ms. Misrak FISSEHA (Moderators) 


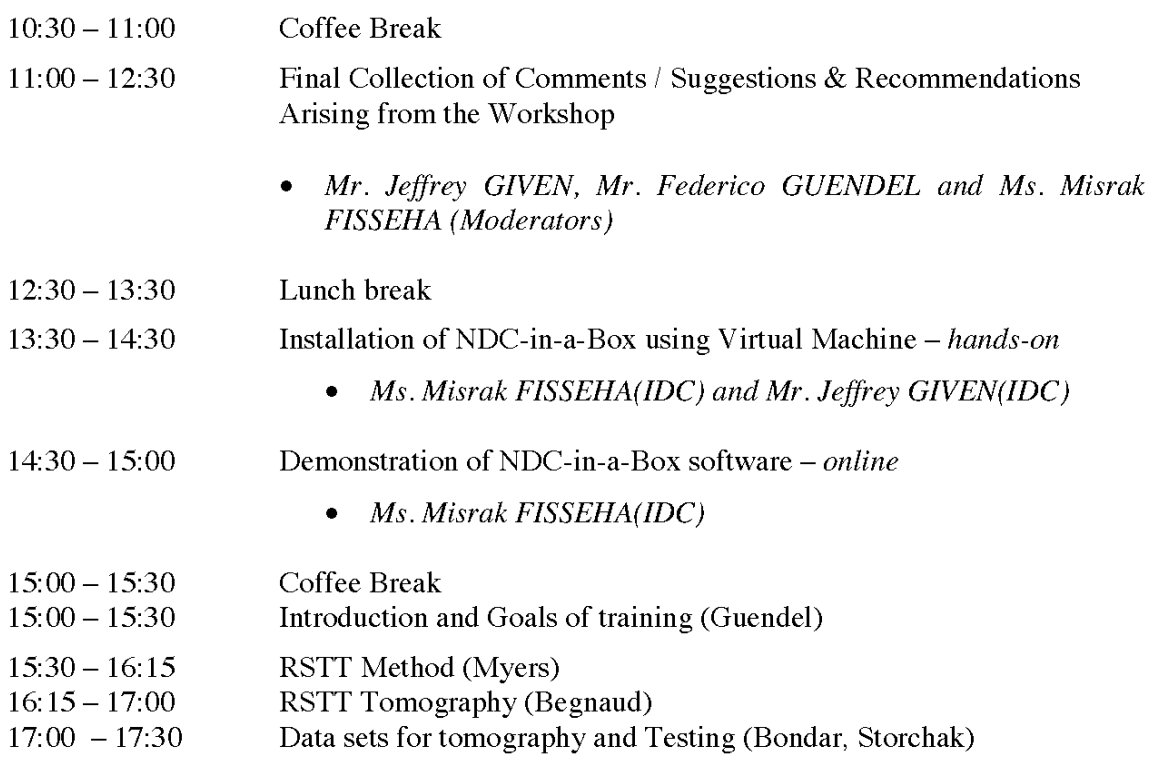

\section{Thursday, 17 October 2013}

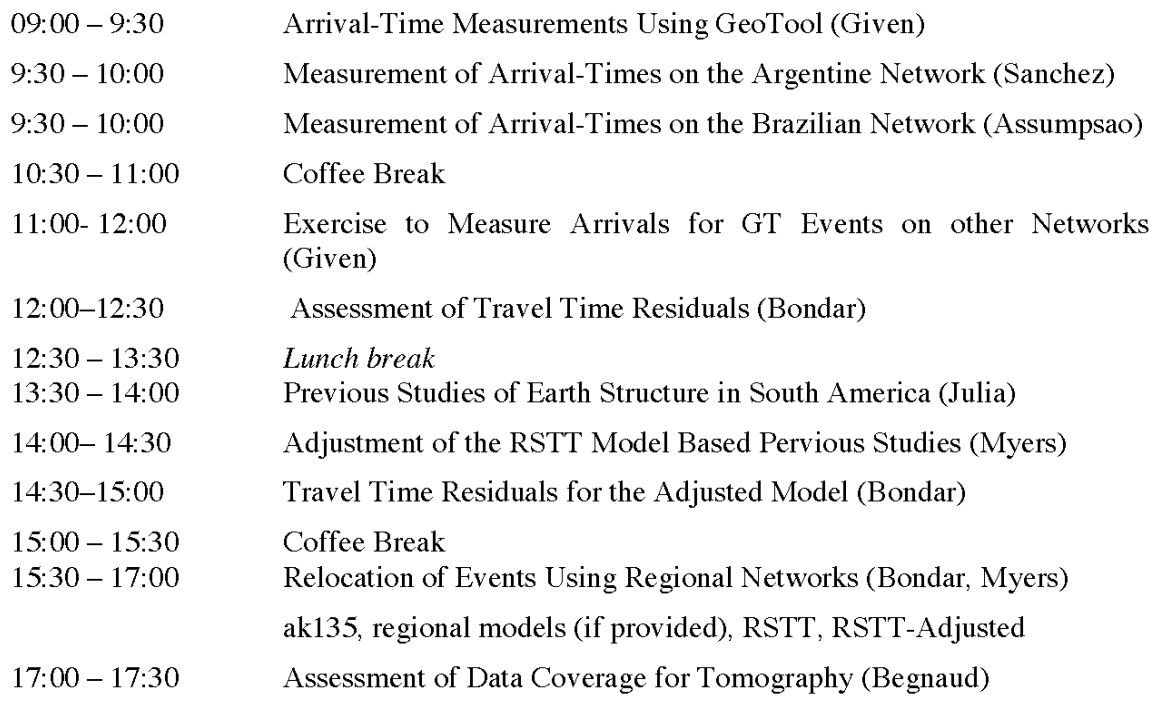




\section{Fridav, 18 October 2013}

\begin{tabular}{|c|c|}
\hline 09:00-10:00 & Use of New Data Set for Tomography (Begnaud) \\
\hline $10: 00-10: 30$ & $\begin{array}{l}\text { Discussion Comparing Models and Travel Time Predictions (Begnaud, } \\
\text { Myers, Bondar) }\end{array}$ \\
\hline $10: 30-11: 00$ & Coffee Break \\
\hline 11:00-11:30 & Discussion on Remaining Regions with Poor Data Coverage (Bondar) \\
\hline $11: 30-12: 30$ & GT data repository at the ISC (Bondar, Storchak) \\
\hline $12: 30-13: 30$ & Lunch break \\
\hline \multirow[t]{3}{*}{$13: 30-14: 00$} & Next Steps (Guendel, Myers) \\
\hline & Comments from participants \\
\hline & Publication? \\
\hline $14: 00-16: 00$ & Wrap -up \\
\hline
\end{tabular}




\section{Appendix III: Selected Photos}

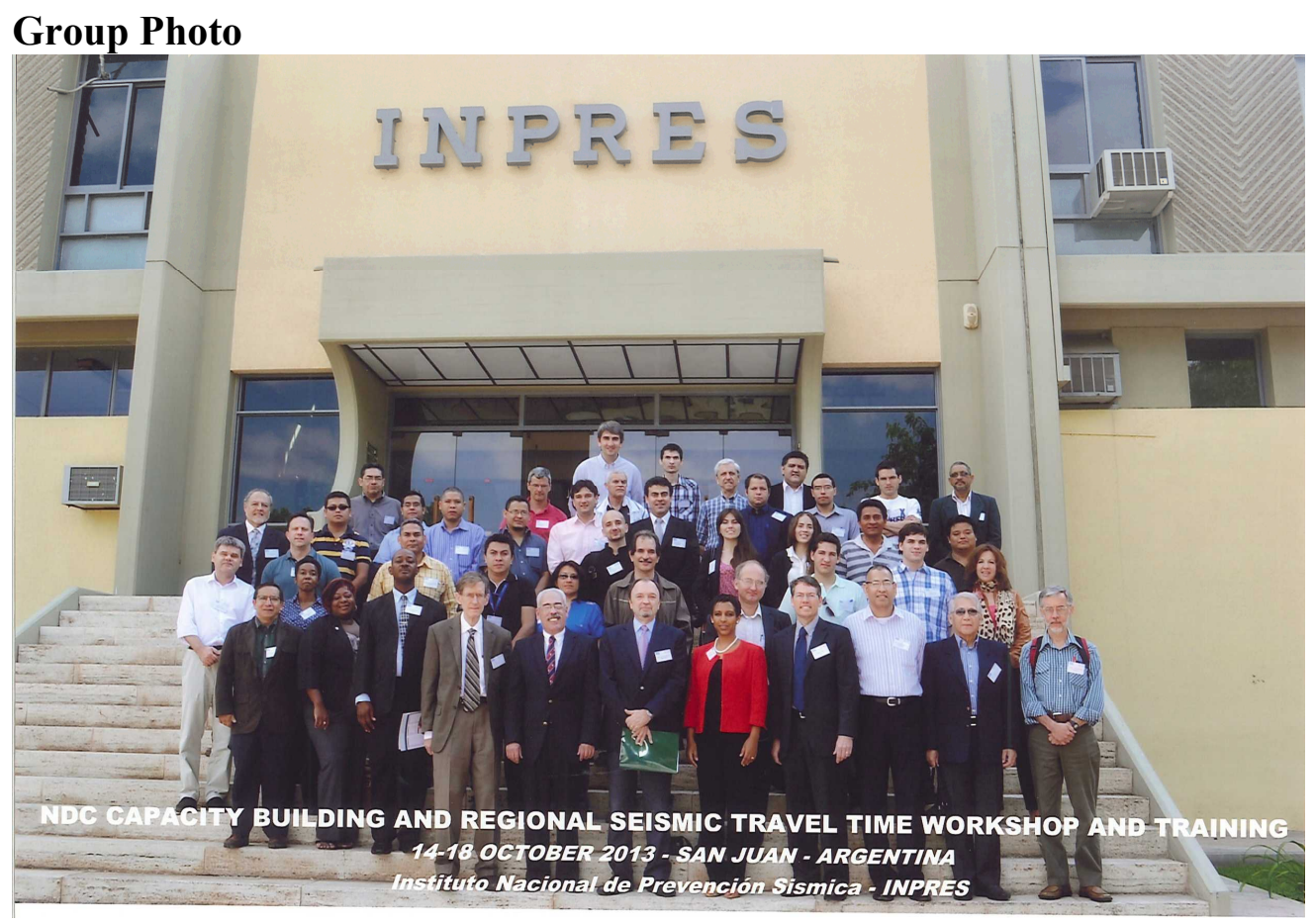

Opening remarks by Mario Bufaliza (INPRES). Jeff Given (CTBTO) and INPRES director Guiliano at the head table.

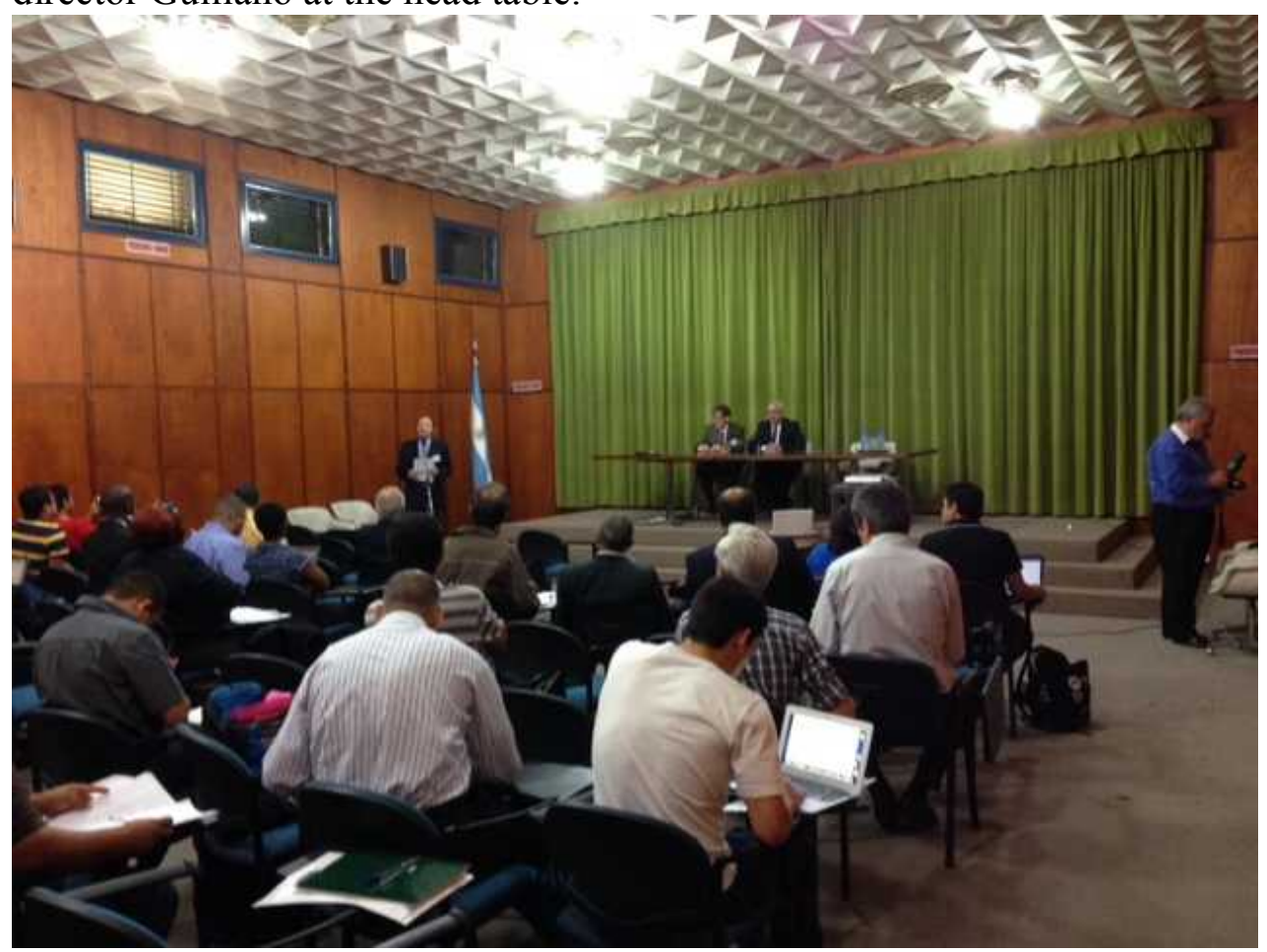


U.S./CTBTO funded students presenting their work

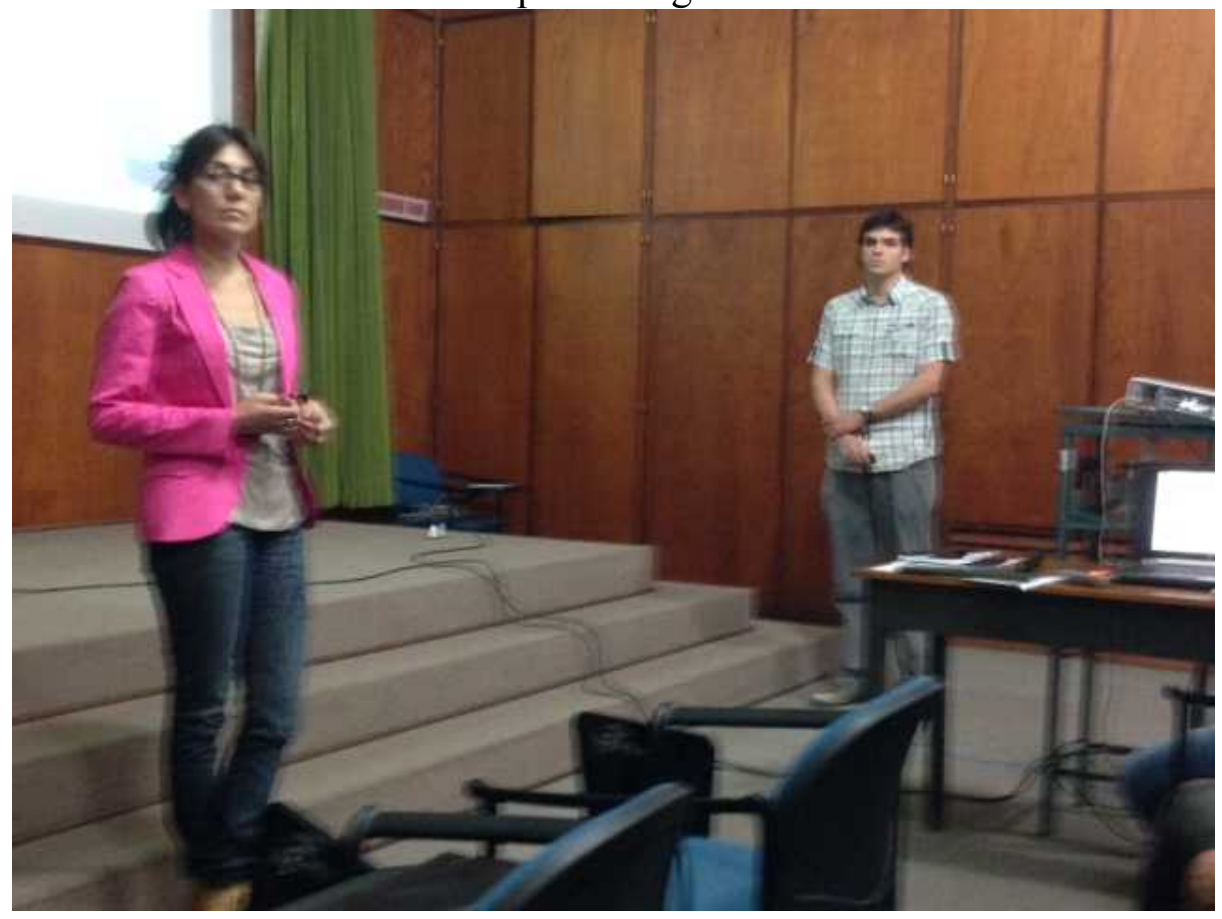

Hands on exercises

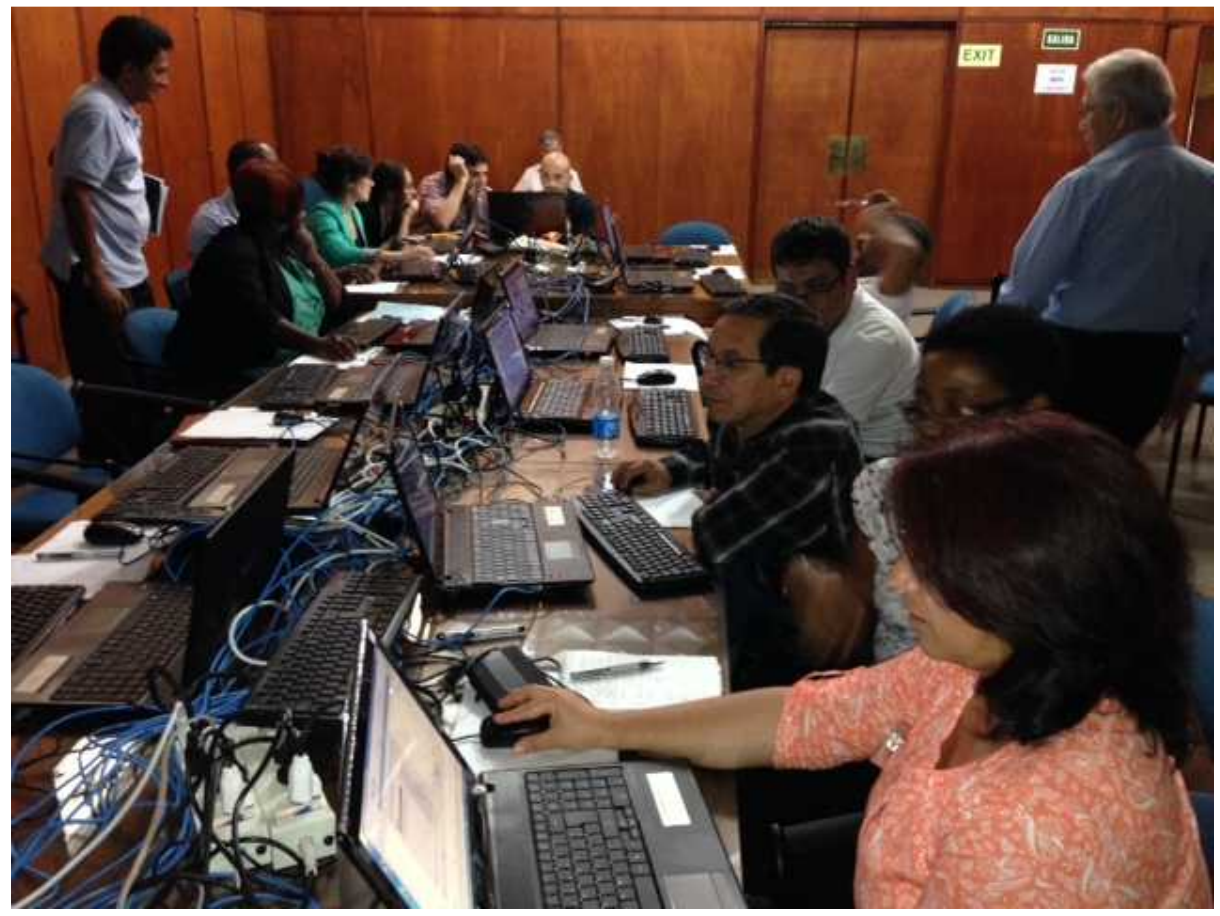

